\title{
Anxiety about English Language Learning among University Students
}

\author{
$\mathrm{Ni} \mathrm{Na}$ \\ Qingdao Technical College,Qingdao266000
}

\begin{abstract}
This study is designed to identify and compare the levels of anxiety experienced by a randomly selected sample of second and third-year English leamers in Nanyang Institute of Science and Technology and to investigate the independent and interactive effects of gender factor with language proficiency on the levels of language anxiety. This research has explored a very important but under-developed area of the foreign language anxiety and provided pedagogical implications for English teaching and learning in the Chinese regular university context.
\end{abstract}

Keywords- anxiety, gender, proficiency, English language learning, foreign language anxiety, English language anxiety

\section{AIMS OF THE RESEARCH}

This study is designed to identify and compare the perceptions of second and third-year university students towards feelings of anxiety experienced during English learning as measured by the adapted Foreign Language Classroom Anxiety Scale (FLCAS). Specifically, the first purpose is to ascertain the levels of anxiety experienced by a randomly selected sample of English learners in a regular university setting. The second objective is to investigate and compare the perceived levels of anxiety experienced by the sophomores with the levels of anxiety perceived by the juniors. That is, the study's main objective is to explore the relation between the anxiety that Chinese EFL learners experience and their language proficiency and to find if apprehension diminishes as students progress in the study of English. Another objective is to see whether the students' gender factor independently or interactively with their general English proficiency affect the relation. If substantial levels of apprehension are found, the discussion of anxiety reduction programs is warranted. So this article is also to bridge the gap between research findings and classroom practice by enabling teachers to identify the sources and manifestations of their students' English Language Anxiety (ELA) and helping teachers to find suitable ways of handling this educational problem within the limits of their classrooms. It is hoped that the present research can contribute to this relatively under-cultivated area in China and provide some usefulhelp for the EFL teaching and learning.

\section{RESEARCH OBJECTIVES}

\section{A. Research questions}

For the objectives of this research, the following questions are raised: Do university students feel anxious in their English language learning? If anxiety exists, what factor has the most impact on students' anxiety in learning English? Is there a difference between levels of English language anxiety experienced by sophomores and juniors? If differences occur, do the students' anxiety levels decline as their English proficiency increase? Does gender factor affects, either independently or interactively with language proficiency, the levels of English language anxiety? The present study is designed to ans wer these questions.

\section{B. Hypotheses}

For the present study, the following hypotheses are proposed: The null hypothesis postulated and tested to determine if there are differences between the sophomores and juniors in the perceptions they hold towards English language anxiety is "there is no significant difference of perceptions between sophomores and juniors for each one of the adapted Foreign Language Classroom Anxiety Scale (ELCAS) thirty-three variables towards anxiety in English language learning." If the anxiety levels of the juniors were significantly lower than the anxiety levels of the sophomores, it could be argued that English language anxiety would have diminished or dissipated as students' English language experience and proficiency increase. On the other hand, if the levels of anxiety shown by juniors were similar to or higher than the levels of anxiety shown by the sophomores, it could be argued that English language anxiety does not necessarily diminish with increased experience and proficiency during the one year of English language learning.

Students experience most anxieties in the construct of communication apprehension.

Gender differences do not affect, either independently or interactively with language proficiency, the degrees to which Chinese learners feel anxious in the English language class.

These hypotheses have their foundations not only in the literature covered in Chapter Two, but also in our common observations and judgments.

\section{THE SETTING AND SUBJECTS}

The subjects in the present study are 185 undergraduates of English major in Nanyang Institute of Science and Technology (NIST). According to the gender factor and the proficiency factor, they fall into four groups: 107 secondyear students (34 males and 73 females), 78 third-year students (19 males and 59 females), 53 male students, and 132 female students.

The subjects are from 18 provinces, municipalities, or autonomous regions in China and are all native Chinese speakers. In age, they range from 18 to 24 with a mean age of 21 years. Before passing the national entrance 
examinations and being enrolled in the university as cadets, all the subjects had learned English for six years in the middle and high school.

As the English proficiency level counts as a variable in the current investigation, juniors and sophomores are chosen to make sure that definite differences in their EFL proficiency are pronounced. The former is treated as the high-proficiency group and the latter the low-proficiency group. Because there perhaps exist some degrees of difficulty in understanding the English version of the adapted FLCAS and to ensure the validity and reliability of the research, freshmen are not chosen into the sample.

The Department of Foreign Languages of NIST began its enrollment of undergraduates of English major in 2001, so there have been no seniors until now and juniors are of the highest grade. There are altogether 112 second-year (36 males, 76 females) and 82 third-year (20 males, 62 females) English majors. For this reas on or that, 185 students of them completed this questionnaire.

\section{INSTRUMENTS}

\section{A. Form of the anxiety questionnaire}

The questionnaire prompts participants to respond to statements concerning their feelings using the English language and consists of thirty-three items, each of which is answered on a 5-point Likert scale ranging from "strongly agree" (scale point 1) to "strongly disagree" (scale point 5) the middle point being neutral (scale point 3 ). That is, in the questionnaire, five possible responses to each question are presented. From them, the subjects are required to choose one to indicate whether they "strongly agree", "agree", "neither agree nor disagree", "disagree", or "strongly disagree" with the relevant statement. A student's endorsement in "strongly disagree" is equated with a numerical value of five; "disagree" was four; "neither agree nor disagree," three; "agree" two; and "strongly agree" was one.

The purpose of the scale is to examine the scope and severity of English language anxiety. For each subject, the anxiety score is derived by summing his or her ratings of the thirtythree items. Anxiety scores lower than 3.0 would indicate some level of an xiety for questions $1,3,4,6,7,9,10,12,13$, $15,16,17,19,20,21,23,24,25,26,27,29,30,31,33$. Anxiety scores higher than 3.0 would indicate some level of anxiety for questions $2,5,8,11,14,18,22,28,32$. To facilitate the statistical analysis, for the questions $2,5,8,11$, $14,18,22,28,32$ in the latter instance, that is, when statements of the FLCAS are negatively worded, responses are reversed and recoded, so that in all instances, a low score represents high anxiety in the English classroom. For example, if a student' s response to question 2 "I don't worry about making mistakes in the English class" is scale point 4 (it means this subject disagrees with the statement and shows some level of anxiety for this question), his/her answer is reversed to 2 . This result is consistent with the overall tendency that a low score means high anxiety and with the subject's actual feeling towards the question (in this case, he/she feels some level of anxiety).

\section{B. Contents of the anxiety questionnaire}

The 33 statements in the questionnaire are adapted from the Foreign Language Classroom Anxiety Scale (FLCAS). To make the scale more suitable for the EFL situation in China, I modify some parts of it. The terms "language" and "foreign language" used in the original version are consistently replaced with "English". The language spoken in the foreign language class is specified as English. For instance, the original FLCAS item "I never feel quite sure of myself when I am speaking in my foreign language class" is turned into "I never feel quite sure of myself when I am speaking in my English class." To facilitate my writing the paper, I call this questionnaire the English Language Classroom Anxiety Scale (ELCAS). Considering that some subjects' English proficiency, especially some sophomores' proficiency, may not be adequate for a correct understanding of the statements, some difficult points in the anxiety questionnaire are explained in Chinese or in simple English.

The background questionnaire includes questions on the student's age, sex, grade, academic major and status, and personal information concerning their English learning.

\section{Validity and reliability of the questionnaire}

The present study, using 185 students of English, yields internal consistency of $.94(x=94.27$ and s.d. $=16.52)$, using Cronbach's alpha coefficient. The reliability, mean, standard deviation, and range obtained in this study are very similar to those of Horwitz ${ }^{[18]}$, who used students enrolled in an introductory Spanish class. The mean of this study, 94.27, is similar to that of Horwitz's study, $x=94.5$. The result demonstrates that the adapted FLCAS is satisfactorily valid and reliable enough to measure the English language anxiety perceived by Chinese university students.

\section{EXPERIMENT AL PROCEDURES}

My experimental study follows a three-phrase procedure. At the first phase, the ELCAS an xiety questionnaire, adapted and modified from the original version of the FLCAS, is prepared and used. Subsequently, the questionnaire answer sheets are collected and scored. At the second phrase, the data collected from the measuring of English language anxiety is processed in the computer for statistical analyses. The third and final part is completed with interviews of the selected teachers and students to discover what specific situations cause English language anxiety in the students and strategies that teachers and students use to alleviate the anxiety.

\section{A. Data collection}

Shortly after the construction of the adapted FLCAS and the identification of the participants, a pilot study is administered to a group of students whose composition is quite similar to the 185 subjects in this study. The pre-test goes smoothly. No problems arise. This proves that the anxiety questionnaire is easy to understand and causes no ambiguous interpretations.

Then the actual measurement of an xiety begins. The ELCAS (see Appendix II) is administered during class time the third week of the fall semester 2003. Subjects are asked to 
complete both an ELCAS and background questionnaire and they are free to ask questions and request clarification on items. The subjects are told that the questionnaire is merely part of an empirical investigation and they do not need to worry about the correctness of their answers. What is required of them is simply to do the questionnaire in accordance with their real experiences. Moreover, the method to do the questionnaire is explained in great detail to prevent any possible misunderstanding of the instructions placed at the opening part of the questionnaire. No time limit is set for the task. In reality, the whole process takes about forty minutes.

Finally, the questionnaire sheets are scored. For a positively worded statement, such as "I worry about the consequences of failing my English language class," the subjects who respond with "strongly agree" are awarded one point, "agree" two points, "neither agree nor dis agree" three points, "disagree" four points, and "strongly disagree" five points. For a negatively worded item, such as "I don't worry about making mistakes in English class," scoring is reversed. It follows naturally that a low point indicates a high level of anxiety. For each subject, the scores are obtained by summing up the points that he/she gets for the statements.

After the administration of the anxiety questionnaire, twelve teachers of different courses and twenty-three students of different language proficiency are selected to participate in the interview, among which fifteen students are from the three classes of Grade Two and eight from the two classes of Grade Three. The students are selected according to their language achievement whose course scores are obtained from their teachers. They are interviewed regarding the specific situations that cause the students to become anxious and strategies they use to ease the language anxiety in the students. Prior to the interviews, permission is obtained from the teachers and students to audiotape responses in order to ensure accuracy.

\section{B. Data analysis}

The data obtained from the raw scores of the survey are processed in the computer for statistical analyses using the Statistical Product and Service Solutions (SPSS Statistical Package, Version 11.5). Firstly, descriptive statistics, main ly means and standard deviation for the general an xiety levels measured by the ELCAS are obtained. Then three major statistical tools are utilized for inferential computations.

Means analysis in compare means process is resorted first to obtain the mean scores and standard deviation for the thirtythree ELCAS questions by proficiency group and gender group.

When estimating the validity and reliability of the newly adapted ELCAS, I make use of Pearson's product-moment correlation and Cronbach's alpha coefficient.

Then one-way analysis of variance (ANOVA) is run to determine whether the means of each of the thirty-three questions between the two pair-wise groups (sophomores vs. juniors and males vs. females) are significantly different at a 0.05 probability level. In social sciences, statistical studies commonly set $\mathrm{p}=0.05$ as the criterion significance level. When $\mathrm{p}<0.05$, the difference is significant. If $\mathrm{p}<0.01$, the difference is highly significant. When $p<0.001$, the difference is very highly significant. The current investigation follows the practice. ANOVA values for the thirty-three variables of the ELCAS significantly lower than $\mathrm{p}$ reject the null hypotheses at the 0.05 probability level. Values found not to be significant indicates that the perceptions of the pair wise-compared groups are statis tically similar.

Pearson's product-moment bivariate correlate analysis is used to investigate the interactive effects of the gender factor and the proficiency factor on the levels of language anxiety that Chinese students experience in the English class, that is, the correlation among the gender, proficiency and English language anxiety variables.

\section{TENT ATIVE CONCLUSIONS}

On the basis of the empirical study, I venture the following conclusions:

Some levels of English language anxiety are experienced by the university students in response to some aspects of English language learning, no matter they are sophomores or juniors, males or females, and their anxiety levels are of moderate degree.

Factors that have an impact on students' anxiety in learning English are communication apprehension, test anxiety and fear of negative evaluation. The construct of communication apprehension has the most impact on students' English language anxiety.

There is no significant difference of perceptions between sophomores and juniors for the ELCAS towards anxiety in English language learning, that is, the language anxiety does not necessarily decline as students progress in the English language learning.

Gender differences do not affect, either independently or interactively with language proficiency, the degrees to which Chinese learners feel anxious in the English language class.

When asked what strategies they used to alleviate anxiety, the teachers' answers were nearly identical to the students' answers. Almost every teacher said that they used many different strategies throughout their instruction that included giving learning strategies, repeating the message, using Chinese as a last resort, encouraging participation, praising correct answers, and responding positively to incorrect answers. They also said they do outside tutoring, give websites for additional practice, and try to establish an environment of mutual respect. Some teachers allowed their students to listen to music during more "relaxed" activities. They also modeled activities frequently before having the students do them. Mnemonic devices were incorporated such as songs, and even humor was a commonly used technique. All of the teachers encouraged participation, responded positively to incorrect answers, and praised correct ones.

\section{REFERENCES}

[1] Aida,Y. Examination of Horwitz, Horwitz \& Cope's construct of foreign language Modern Language Journal, 1994, 78: 155-168.

[2] Bellanca, J. Building a caring, cooperative classroom. Palatine: Skylight Publishing, 1991. 
[3] Boud, D. The use of self-assessment schedules in negotiated learning. Studies in Higher Education J, 1992, 17 (ii): 185-200.

[4] Brown, H. D. Teaching by principles: An interactive approach to language pedagogy. Englewood Cliffs, NJ: Prentice Hall, 1994.

[5] Campbell, C., \& Kryszewska, H. Learner-based teaching. New York: Oxford University Press, 1992.

[6] Campbell, C. M. \& Ortiz, J. Helping Students overcome foreign language anxiety: a foreign language anxiety workshop. In E.K. Horwitz \& D.J. Young (Eds.) Language Anxiety: From theory \& research to classroom implications Englewood Cliffs, NJ: Prentice Hall, 1991.141-150.

[7] Campbell, C. Language Anxiety in Men and Women: Dealing with Gender Difference in the Language Classroom. Affect in Foreign Language and Second Language Learning: A practical guide to creating a low-anxiety classroom atmosphere. Boston: McGraw-Hill College, 1999. 191-215. 